\title{
Research on the Cultural Implication of Urban Image in Modern Media*
}

\author{
Sheng Huang \\ Fuzhou University of International Studies and Trade \\ Fuzhou, China 350200
}

\begin{abstract}
Urban image refers to the urban space in audiovisual media art. Under the background of rapid development of new media, the existence of urban image is gradually diversified. With the rapid growth of the media, the cultural connotation and aesthetic characteristics of urban image have changed in varying degrees, from the past direct utilitarian performance to the alienation and dispersion in the new media environment, which has promoted the urban image to become more vivid and rich in connotation. Based on this, this paper elaborates the development process of urban image culture connotation in modern media so as to assist to shape a good urban image, disseminate and promote regional culture.
\end{abstract}

Keywords—modern media; urban image; cultural connotation

\section{INTRODUCTION}

In the context of the global media era, the media has developed rapidly. Film and television works based on modern media promote the widening of artistic creation space. Through the artistic creation of audio-visual media, the real world can be simulated so that the vivid depiction of the external world in different time and space will be realized. In film art works, as the most basic narrative space, the city images created in the film world objectively reveal the political and cultural characteristics of a specific historical period. Therefore, while narrating, the urban space in the film works will inevitably reflect the corresponding cultural temperament and historical atmosphere. In the diversified development of modern media means, the cultural connotation contained in urban images is more and more abundant, which plays an important role in shaping a good city image. Strengthening the research on the evolution of urban image culture connotation in modern media can provide a basis for the study of subsequent urban cultural connotations and regional characteristics.

\section{URBAN IMAGE CULTURE IN MOVIES}

Since the modern machine revolution, the level of productivity has been continuously improved, and many disciplines such as physics, optics, chemistry, mechanics, and electronics have been continuously developed, which finally led to the birth of the "seventh art" film. From the first time

*2018 School-level Education and Teaching Reform and Research Project: Establishment and Construction of a Practical Teaching System for Photography Courses Based on "Applied Undergraduate Universities" (Project No. : JF2018044). that the Lumiere brothers showed the film "the Arrival of a Train" with their own invented machine for dual-purpose of projection and shooting in the "Grand Cafe" in Paris, many filmmakers began to focus on the familiar urban life, so their works tend to have a strong flavor of life. Because in their eyes, movies were a kind of business behavior, so, in order to get a good business return, they often aimed at the familiar urban life. Since modern times, the scale of cities has been expanding, and the population has increased dramatically. At the same time, the social division of labor has gradually become more meticulous. With the support of modern production methods, unique urban civilization has gradually formed, which is significantly different from agricultural civilization. [1] In this context, people living in the prosperous urban life correspondingly begun to enjoy the economic and emotional relationship of more and more urban civilization features, which to a certain extent focused on the characteristics of modern human civilization. In the film art creation, the integration of human urban life images helped to objectively reveal the human life state and social environment. In this way, it can not only be understood that whether the city had enough accommodation space, but also showed people's interpersonal relationships in specific situations and grasped the characteristics of specific historical periods. So space itself had a historical flavor. Some excellent movies record these cities with more historical and cultural characteristics in the movies, which set off a heated wave of movies, such as the Shanghai series in the Republic of China, the modern film series of American cities and Paris in Hollywood age. Through different forms of expression, these films presented modern urban life intuitively in front of people and depicted a beautiful modern urban scene. Whether it was old Shanghai leading a voluptuous life or fantastic Paris, such excellent films record the stories of modern cities, making the audience involuntarily participate in the construction of urban culture and feel the cultural connotation and characteristics of the city. For example, the 2002 film "City of God" shows the slums of Rio de Janeiro, a city of God and capital of sins in Brazil by means of wild and heavy brushwork with criminal and thrilling scenes. Many outstanding films show the vivid images of cities such as London, New York, Moscow and Shanghai in front of the audience. For these world-famous metropolises, their urban culture and urban style have been shaped in many films, so that some of the labels in the film have become the distinctive imprint of these cities, which has an important role in promoting the spread of urban culture. 
Both in the field of photography and movies, the "city image" is integrated with the connotation of urban culture, recording the historical changes and cultural connotations of the city. In the field of photography, some scholars believe that urban image is a kind of "collective memory". Through the expansion of images, they can express the interpretation of real life and humanistic care. [2] For example, young photographer Benny Lin records the lower class of Hong Kong society in a different visual language: a family of four members can only live on a double bed. It is dirty, crowded, chaotic and helpless, which constitutes the other side of Hong Kong's urban life of humble abode and polarization between the rich and the poor. In the field of film, some scholars make interpretation from a cultural perspective. They are inclined to analyze the connotation of urban culture involved in the film, and explore the social situation and people's survival state combined with people's living conditions. For example, through the analysis of modern scenes and the crowded Shikumen Lane in Shanghai-based movies during the Republic of China and other diversified living spaces, the film viewer can understand the living conditions of Shanghai residents at that time, which provides a basis for the early imagination and analysis of the urban environment of Shanghai. [3]Based on this, it is not difficult to see the potential relationship between urban history and culture and urban image, that is, the city in the film is the background of the film story, which promotes the relationship between the characters in the film to be more vivid and to set off the situation. Films such as "L. A. Confidential" and "Battle: Los Angeles " bring people deep emotional experience through the foil and rendering of the violent and criminal city of Los Angeles. In this way, the city itself is taken as the background of the film story, and the city landscape with more peculiar shape is created as far as possible. The city environment, the status of the characters and the life movement are integrated to highlight the connotation and the main body of the film, while creating the aesthetic scene. The film brings unique aesthetic enjoyment because the different elements set off against each other. This method of film creation is the main way of dealing with city images in movies, and is favored by film directors.

International metropolises such as New York, Shanghai and Tokyo have attracted the attention of a large number of international directors. They focus on the lens, artistic creation of the city's individual image, leading the audience to sort out the development process of urban culture from the perspective of the film, and constantly present and write the image of the city at each stage in the film. Making a comprehensive survey of the development of film history, it is not difficult to see that the film and the city image are inseparable. While embossing the urban cultural temperament and shaping the city culture, it also further enriches the film's connotation. Urban imagery provides services for the plot of the film. After a large number of films have been successful, such as "Finding Mr. Right", "Chung King Express", "Sleepless in Seattle", "Notting Hill", etc., excellent directors and producers begin to directly use the city as an artistic creation and performance object, such as "New York Stories", "New York I Love You" and "Paris, Je T'aime" and so on. The creation of these films is entirely based on highlighting the urban temperament style and cultural characteristics. The artistic life of the urban people is created in front of the audience, allowing them to accept it naturally.

\section{URBAN IMAGE CULTURE IN TELEVISION}

When the TV was born, it quickly gained a large audience and seized the market that originally belonged to the movie. By 1960, there were 780 TV stations and nearly 30 million TV sets in America nationwide. About $87 \%$ of households had at least one TV set. The rapidly developing TV art has also attracted a large number of urban video broadcasts. However, compared with that in the film art, the urban imageries of TV art have some changes worthy of attention, like the urban implication and culture shown in the image of the city in cinema: grievances, such as "Morte a Venezia"; alienation, such as "Blow-up"; sin, such as "City of God"; sentiment, such as "Roman Holiday" and so on, the urban imagery in TV art tends to be single, and the cultural connotations displayed are mostly positive spiritual values. In China, image advertising for the city began in 1999. At that time, Weihai City, Shandong Province, made a decision to attract local tourists by advertising to develop local tourism. In order to form differentiated competition, the advertisement adopts "a new creative idea", which was from the simple promotion of individual tourist attractions to the promotion of a city; from the promotion of scenic spots to the promotion of urban image; from the exploration of scenic spots to the discovery of cities Soul. Urban advertising no longer focused just on a certain individual thing in the city, but comprehensively examined the entire city. Through the combination of various resources in the city, it produced an overall impact, displaying the whole city image." [4]Starting from "Weihai CHINA", a large number of city image propaganda films began to appear in TV art and they were regarded as one of the best carriers for the city to promote its own culture. According to the survey, "only from 2007 to 2010, the number of CCTV city image advertisers increases from 237 to 306, with a growth rate of $29.1 \%$. The corresponding total length of city image advertisements has also increased year by year, and the momentum is fiercer than the number of advertiser, from 177.5 hours in 2007 to 455.9 hours in 2010 , with a growth rate of $156.9 \%$."[5]

The current city image advertising video are basically divided into four categories: the first one is urban propaganda footage, which is generally hosted by the city government to provide a comprehensive statement on the city's politics, economy, urban construction, culture, history, and humanities; the second one is city tourism image film. Led by the city government or the city tourism department, a tourist scan of the city's main landscape is conducted. The third category is the city investment canvass video, focusing on the introduction of urban economic and trade development and showing the city's advantageous resources as well as good investing climate. The fourth kind is a city image propaganda film that matches large-scale events, such as the city image propaganda film of Beijing before and after the 2008 Beijing Olympics, and the Shanghai city image ad before the 2010 Shanghai World Expo. The emergence of a large number of city image propaganda films can be seen as the second transformation of the urban image aesthetics. This image expression needs are consistent 
with the TV media attributes, attracting the attention of governments across the country and becoming an effective means of boosting city's soft power and expanding the city visibility. The city propaganda film has made a major contribution to the shaping of the city image and cultural communication with the achievement of considerable publicity in media communication and is an art that actively uses audiovisual images to display the image of the city. Many city image propaganda films show the advantages of the city at different levels and at different angles, and some fine products have emerged. [6] However, because it is still in the primary stage, there are also two main problems. First, the level of production is lacking. In the narrative, if the propaganda film is only a simple combination of scenic spots, industrial plants, and urban architecture, in this era of so many city image propagandas, it is impossible to attract the attention of the audience. The Fuzhou City Government's "Welcome to Fuzhou" talks about Fuzhou's scenic spots, industrial achievements and folk customs. From the perspective of the city image propaganda film, the film is not bruised, but it fails to bring a good visual impact force to the audience, so the film can only be regarded as a straight and narrow works. "Photographing is a very important technical link in the city image propaganda film. It is the process of transforming the static text plan into a dynamic image and transforming the urban spirit as well as urban connotation into a visual picture." [7] Therefore, in the production process of the image propaganda film, it is necessary to tell whether the narrative is dull, whether the rhythm is appropriate, and whether the angle is novel or not. The second is to just show high-rise buildings, scenic spots and no person to be seen. Some city image propaganda films will focus on buildings and scenic spots, and there is no or very few citizens, who are the masters of the city. Such films seem to be very beautiful, but they lack of urban connotation in essence indeed. That's because the city is composed of people and people are the embodiment of urban culture, so, only by highlighting people, the culture of a city can be reflected.

\section{URBAN IMAgE CULTURE IN THE INTERNET AGE}

With the Internet and mobile Internet becoming the mainstream, the new media is becoming more and more prosperous, turning into the dominant media, which brings a broad space for urban image communication and propaganda, and promotes the cultural connotation of urban image to a higher level. Compared with traditional media such as movies and television, urban images in the new media era are easier to disseminate and have a wider range of dissemination, but in the mean time, they are more fragmented. In terms of content, new media is richer than traditional media, and can transmit more information at one time than traditional media. Moreover, it's also more convenient in speed. Unlike traditional media, which presents urban images in a comprehensive and complete way, new media exists in the form of databases and hyperlinks to pass to the users, in a form of more user-friendly and popular, including micro-movies, short videos, and themed photography and so on. Compared with traditional media, the new media's characteristics of sharing, interactivity, and immediacy can better disseminate urban images, and more delicate and closer to users, allowing users to further understand urban cultural connotations through multiple channels.

Based on this, it is necessary to transform the situation that in traditional film and television media era, too much attention to the propaganda role of urban imagery is paid and the form of expression is single. It will be better to disseminate urban images through the Internet and smart phones. To increase the sense of participation of the masses with the use of Weibo, WeChat, short video and other propaganda methods will help strengthen the sense of ownership of the citizens, thus making them spontaneously disseminate urban images and enrich the cultural connotation of the city. At the same time, it's crucial to grasp the law of new media information dissemination and change the shape of urban images in order to better adapt to the new media environment. For example, by photographing urban micro-movies, the relationship between the city and the people is described, so that a story-like feeling of flowing water will be offered while showing the life of the city people, which is more easily accepted by people. The urban image created in this way will be more intimate and harmonious, extremely beneficial to the improvement of urban culture.

\section{CONCLUSION}

In the modern media environment, media forms are gradually diversified and media behaviors are becoming more abundant. Due to the reduction of communication costs, the promotion and advertising of urban imagery is more convenient, which requires the local government to fully integrate its own resource advantages, transform the marketing promotion concept, and make full use of modern media means to shape a good city image and enrich the city cultural connotation.

\section{REFERENCES}

[1] Liu Haisu. Urban Image Expression and Urban Culture Dissemination of Chongqing in New Century Films [J].Tourism Overview(the second half of the month), 2018, 15 (02): 237. (in Chinese)

[2] Wang Weiqiang. Urban Image and Urban Criticism [J].Beijing Planning Review, 2015 (4): 6-11. (in Chinese)

[3] Zhao Xuan. Elite Politics, Vernacular Modernism and Postmodern Vision - On the Spatial Presentation and Cultural Politics of Nanjing City Image in the Republic of China[J].Sichuan Drama, 2017, 25 (01): 82-86. (in Chinese)

[4] Zhou Yi, Huang Wei. Urban Image Advertisement in Urban Development - The Birth of China's First City Image TV Advertisement and Its Impact Analysis [J].Press Circles, 2007 (2): 107-108. (in Chinese)

[5] Wen Chunying, Liu Xinxin, Yang Yanchao, Zhang Xufang, Zhang Shumei.Analysis of China's City Image Advertising Distribution Taking CCTV City Advertising in 2007-2010 as Examples [J]. Modern Communication, 2012, 34 (6): 91-94. (in Chinese)

[6] Sun Yuke, Xu Man, Liu Huanli. Analysis of Image Construction and Communication Effect of Urban Culture under the Perspective of Value Establishment[J].Education \& Teaching Forum, 2015, 31 (34): 54-55. (in Chinese)

[7] Cao Yimei, Yang Yang. An Analysis of the Problems Existing in the City Image Advertising Video - Taking the City Image Advertising Video of Henan Province as an Example [J]. Media Time, 2013 (4): 4345. (in Chinese) 